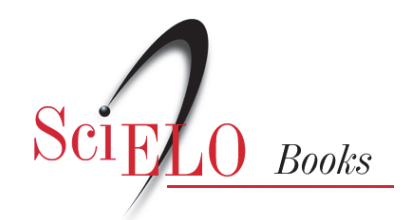

\title{
Seduepb
}

\section{A vida de José segundo Robert Coover}

\author{
Delzi Alves Laranjeira
}

FERRAZ, S., et al.,orgs. Deuses em poéticas: estudos de literatura e teologia [online]. Belém: UEPA; Campina Grande: EDUEPB, 2008. 364 p. ISBN 978-85-7879-010-3. Available from SciELO Books $<\underline{\text { http://books.scielo.org }>\text {. }}$

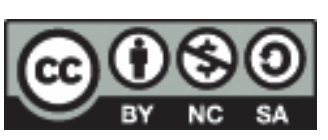

All the contents of this work, except where otherwise noted, is licensed under a Creative Commons Attribution-Non Commercial-ShareAlike 3.0 Unported.

Todo o conteúdo deste trabalho, exceto quando houver ressalva, é publicado sob a licença Creative Commons Atribuição Uso Não Comercial - Partilha nos Mesmos Termos 3.0 Não adaptada.

Todo el contenido de esta obra, excepto donde se indique lo contrario, está bajo licencia de la licencia Creative Commons Reconocimento-NoComercial-CompartirIgual 3.0 Unported. 


\section{A vida de José segundo Ro- bert Coover}

Delzi Alves Laranjeira 
- ofir obmuger geolg jo shiv. tevoodyiget

Driginionod zoula jalge 
Resumo: No conto J's marriage, o escritor americano Robert Coover faz um recorte da história de Jesus e direciona o foco para um personagem pouco mencionado na narrativa evangélica: José, o marido de Maria. Tendo como base o Evangelho de Mateus, Coover suplementa os vazios do texto bíblico, apresentando ao leitor um José radicalmente diferente daquele que foi legado pela tradição evangélica. Sem sonhos nem anjos que certifiquem seu papel nas vidas de Maria e Jesus, José, que percebe o mundo sob uma ótica existencialista, luta para compreender o abismo que o separa de sua esposa e porque, afinal, sujeitou-se à uma vida tão infeliz.

Palavras-chave: reescrita, evangelhos, subversão.

Abstract: In the short story J's marriage, American writer Robert Coover focuses on a secondary character in the gospels' narrative: Joseph, Mary's husband. Based on Matthew's account, Coover fills in the gaps in the biblical text, presenting to the reader a radically different Joseph. Without dreams or angels to guide him about his role in Mary's and Jesus' lives, Joseph, or J, whose world view is an existentialist one, struggles to apprehend the gap between himself and his wife and why, after all, his life ended up being so miserable.

Key words: rewriting, Gospels, subversion.

* Doutora em Literatura comparada pela Universidade Federal de Minas Gerais. Pesquisadora nas áreas de literatura comparada e literaturas de expressão inglesa com foco em reescritas ficcionais das narrativas bíblicas. Email: da.laranjeira@uol.com.br 
Quando Robert Coover iniciou sua carreira de escritor no final dos anos 50 duas tendências concorriam na ficção americana: os escritores realistas, representados por Norman Mailer e Truman Capote, que produziam um tipo de escrita "às vezes denominada jornalismo subjetivo, às vezes chamada de romance de não-ficção (que poderia ser chamada de ficção objetiva)" (Kennedy, 1992, p. 3) ${ }^{191}$, e um outro grupo que definia a realidade em outro nível: como um construto, um artefato, e não como simples percepções da vida cotidiana.

Coover pertence ao segundo grupo, juntamente com John Barth, Donald Barthelme, Kurt Vonnegut e Thomas Pynchon, entre outros. Estes escritores desvencilharam-se do realismo convencional e mudaram o foco para a metaficção, tornando-se referências da primeira geração de escritores pós-modernos, que tomaram a cena literária americana nos anos 60 e 70. Coover, no entanto, não se limitou às questões metaficcionais. Para L. L. Lee (1986, p. 63), suas obras são mais "do que questionamentos ou negações de sistemas de valores humanísticos corporificados pela linguagem, elas também são reivindicações, e, freqüentemente, afirmações sobre a existência humana para além das fronteiras da linguagem" ${ }^{192}$.

Entre os três grandes temas que a obra de Coover explora, segundo Lee, está a apropriação de conteúdos do passado: a Bíblia, contos de fadas, obras de outros autores. Tais conteúdos, no entanto, não operam como simples alusões: paradoxalmente, Coover utiliza fórmulas aparentemente esgotadas com o intuito de revelar que elas contêm várias camadas de sentido, como demonstram suas releituras e reescritas de Chapeuzinho Vermelho, João e o Pé de Feijão, o dilúvio em Gênesis, a história de Jesus nos evangelhos.

J's marriage é uma reescrita do Novo Testamento que segue a mesma estratégia de outros contos como The brother e The reunion: uma história bíblica familiar é recontada a partir de um ponto de vista não-familiar (McCaffery, 1982. p. 62), subvertendo as interpretações amplamente consolidadas do texto prévio. O foco de Coover em J's marriage é na história de José, o marido de Maria e pai terreno de Jesus. A história da imaculada concepção, um dogma do catolicismo, é revisa-

191 No original: "sometimes called subjective journalism, sometimes the nonfiction novel (what might be called 'objective fiction')." Todas as traduções de textos em língua estrangeira são de minha responsabilidade.

192 No original: "than questions or denials of humanistic value systems as embodied in language; they are also assertions, and often affirmations, about human existence outside of language". 
da no conto. O Novo Testamento apresenta quatro versões da vida de Jesus: os Evangelhos de Mateus, Marcos, Lucas e João. Segundo Wilkie e Hurt (1992, p.1.203), embora os quatro evangelhos contenham narrativas similares no que diz respeito à Paixão de Cristo (o julgamento, tortura e execução de Jesus) e a sua ressurreição, eles divergem em vários outros eventos da vida de Jesus, incluindo as passagens relativas ao seu nascimento e infância.

No que diz respeito à Maria e José, os evangelhos são bem reticentes. A história tradicionalmente conhecida é que eles estavam comprometidos um com outro e então o anjo Gabriel apareceu a Maria e anunciou que ela daria à luz o filho de Deus, que deveria ser nomeado Jesus (Lc 1,31). Ao tomar conhecimento da gravidez da noiva, José duvidou de Maria e quis rejeitá-la, mas, novamente, a intervenção do anjo coloca José a par dos planos divinos e o convoca a colaborar (Mt 1,19-25).

Dos quatro evangelhos, somente Mateus e Lucas mencionam José. E somente Mateus faz referências à vida sexual dos pais de Jesus. No seu evangelho, Mateus diz que José não a "conheceu”, ou seja, não mantiveram relações sexuais antes do nascimento de Jesus. (Mt 1:25).

J's marriage opera nos vazios existentes na narrativa bíblica, nos ângulos não iluminados que Auerbach menciona em Mimesis. J, que pode ser identificado com o José bíblico, é o protagonista da versão de Coover, sua história trazendo à luz uma faceta da narrativa evangélica relegada às sombras. $\mathrm{O}$ conto de Coover mostra a rotina e os sentimentos de José, chamando atenção para esses aspectos escondidos. A narrativa bíblica é extremamente sucinta, uma vez que o foco é Jesus. José e Maria são secundários, e a participação de José é muito discreta. Em torno dos esparsos detalhes que a Bíblia provê, Coover propõe retratar um José que difere radicalmente do personagem evangélico. Tal perspectiva conduz o leitor a reconsiderar a versão apresentada nas Escrituras

O conto de Coover é sobre $\mathrm{J}$, um homem atormentado pelo fracasso de seu casamento. O leitor informado pela cultura cristã é capaz de reconhecer a referência bíblica na passagem a qual a mulher sem nome comunica a J que está grávida e, a partir daí, estabelecer as conexões entre J e José, a mulher sem nome e Maria. A história começa com a decisão de $\mathrm{J}$ de casar-se com sua amada, embora ele reconheça que as diferenças entre eles não facilitam as coisas: J é bem mais velho e possui um nível de educação bem mais elevado do que a noiva. No entanto, 
está tão apaixonado que minimiza tais aspectos. Para sua grande surpresa, é Maria quem recusa o pedido de casamento, o que leva J a cair em depressão. Ele suspeita que Maria tema qualquer contato sexual e suas suspeitas são confirmadas pela maneira como ela rejeita todas as tentativas de se tornarem íntimos. Ao refletir sobre a rejeição de Maria sem encontrar respostas satisfatórias, J decide que, pelo menos por enquanto, sexo não é fundamental para o relacionamento e propõe que, até que ela se sinta pronta, o casamento não será consumado.

A vida a dois segue calma, feliz e tranqüila ate o dia em que J tenta uma maior aproximação. A recusa de Maria é seguida pelo anúncio da gravidez. J não suporta o impacto e adoece gravemente. A esposa cuida dele com dedicação, e $\mathrm{J}$ melhora aos poucos, até que os papéis se invertem e ele passa a tomar conta de Maria devido ao seu estado. O relacionamento, porém, é indelevelmente afetado. Até a sua morte, muitos anos depois, J tenta em vão compreender os eventos que alteraram e determinaram sua vida tão significativamente.

O estilo narrativo de Coover em J's marriage é elaborado. Alguns críticos o consideram complexo e até Joyceano (Kennedy, 1992. p. 42), enquanto outros chamam atenção para o uso de uma prosa introspectiva para retratar J (Andersen, 1981, p.21). Um narrador em terceira pessoa, onisciente e editorial apresenta os aspectos mais íntimos da vida e da personalidade de $\mathrm{J}$, permeando a narrativa com seus comentários, como na passagem em que $\mathrm{J}$ e Maria partilham o primeiro momento de intimidade depois do casamento:

De madrugada, J, sentando-se do lado da cama (ambos ainda vestidos; obviamente, ainda levaria algum tempo para se aprender a arte do desnudamento), J, transbordando em profunda afeição, começou a acariciar suas têmporas, e com a primeira e tênue claridade do novo dia, ela adormeceu ao lado dele, e J chorou novamente ao perceber o sentido e a importância desse adormecer. ${ }^{193}$

A prosa de J's marriage, segundo Bradbury e Ruland (1992, p. 210), é caracteristicamente modernista, enfatizando a elaboração de uma realidade permeada por complexidades morais, psicológicas e es193 No original: Toward dawn, J, sitting on the side of the bed (both of them still dressed, of course; it would take some while yet to learn that first art of nakedness), overflowing with profound affection, began to caress her temples, and with the first thin light of the new day, she fell asleep beside him, and $\mathrm{J}$ wept again to realize the meaning and the importance of her sleep (COOVER, 1970. p.114). Futuras referências a J's marriage serão abreviadas JM e incluídas entre parêntesis no corpo do texto. 
téticas, visando à descoberta de como a consciência dá forma ao real. Durante a história, os aspectos mais íntimos da mente de $\mathrm{J}$, suas angústias e suas concepções de mundo e sobre Deus, são trazidos à luz. J procura estruturar uma noção de realidade que seja adequada às suas convicções, mas ele fracassa, porque seu destino não pertence a ele, mas a Deus, não importa o tipo de escolhas que faça. $\mathrm{J}$ desconhece as relações entre Deus e sua esposa e próprio papel que exerce nelas.

J's marriage subverte o texto bíblico não somente em termos de estilo narrativo, mas também pelos questionamentos que suscita, principalmente a questão sexual envolvendo J e Maria. Eles são casados, mas, ela ainda é virgem. Em Mateus 1,18, Maria concebeu antes de viver com José, Lucas não esclarece se no anúncio da Natividade o casal já morava junto. O que os evangelhos indicam é que; Maria concebeu logo após o casamento ou não muito depois disso. Uma conclusão, porém, é clara, a partir do relato dos evangelistas: o casamento ainda não havia sido consumado.

Menções sobre sexo no texto bíblico são feitas a partir de eufemismos como "conhecer" ou "ir ter". Adão "conheceu" Eva e ela engravidou de Caim em Gênesis 4,1. Abraão "foi ter" com Hagar, que também engravidou. Sexo nunca é conectado a sentimentos, mas ao casamento e procriação. A maternidade predomina sobre o prazer sexual e qualquer outra visão é considerada pecaminosa. J's marriage subverte o princípio bíblico ao explicitar que o desejo de $\mathbf{J}$ por Maria antecede qualquer preocupação com fecundidade e procriação.

A Bíblia é reticente sobre assuntos relacionados a sexo, mas em J's marriage os detalhes do namoro de J e Maria são claramente expressos. Antes do casamento, Maria rejeita as tentativas de $\mathrm{J}$ de estabelecer um contato mais íntimo - um pecado, do ponto de vista bíblico (e judaico) que $\mathrm{J}$ parece ignorar sem problemas. O comportamento de Maria o confunde e o faz sentir-se péssimo, principalmente porque ela não provê nenhuma explicação para suas recusas. No conto, Maria não expressa suas emoções, ao contrário de $\mathrm{J}$, que reage imediata e profundamente a qualquer fato ligado ao seu relacionamento com Maria. Quando ele propõe casamento e ela pede um tempo para considerar a proposta, J sente-se embaraçado: ele não consegue entender porque ela hesita em aceitá-lo. O narrador sugere que há diferenças sócio-culturais entre eles, que $\mathrm{J}$, de certa forma, encontra-se em uma posição superior à de Maria:

E, embora ela certamente fosse inteligente e es- 
pirituosa, era ele quem detinha um nível de educação bem mais alto. De fato, não seria descortês dizer, e ele o admitiu para si mesmo no tormento de seus momentos mais racionais, ela foi incapaz de compreender a maioria das maravilhosas coisas que ele lhe disse. ${ }^{194}$ (JM, p. 112).

O desapontamento de $\mathrm{J}$ parece derivar da rejeição de Maria, que deveria se sentir lisonjeada por ser a sua escolhida, pelo fato de ele pertencer a uma classe superior. Interpretando erroneamente o comportamento de Maia, J conclui que talvez ela queira mais do que palavras bonitas, forçando um relacionamento sexual mais aberto. Tal perspectiva, porém, amedronta Maria de tal forma que ela recusa toda e qualquer tentativa de $\mathrm{J}$ neste sentido

O leitor que conhece os episódios bíblicos percebe facilmente a situação de Maria: ela precisa ser virgem de forma a cumprir a vontade divina, portanto, não pode ser uma mulher casada. J, por sua vez, está completamente afastado da esfera religiosa e sagrada: a aliança entre Maria e Deus - ela é a escolhida para gerar o filho do Altíssimo - é desconhecida para ele até o momento em que ela lhe conta sobre a gravidez. Assim, ignorante dos acontecimentos que envolvem sua esposa, $\mathrm{J}$ conclui que deve haver algum motivo para que ela recuse a consumação do casamento. Ao refletir sobre o assunto, J considera várias razões para o comportamento de Maria: desorientação devido a discursos deformadores de avós, terrores psicológicos, tais como um pai dominador e até mesmo temor pelas "torturas do mundo das trevas" (JM, p.113), ${ }^{195}$ uma possibilidade que incita um comentário do narrador que estabelece uma conexão entre o conto de Coover e os personagens bíblicos. Embora a mulher amada de J não seja nomeada, o comentário do narrador de que "a situação da mulher na história fornece motivos para se pensar a respeito" 196 (JM, p.113) pode ser interpretado como uma dica de que a mulher em questão é Maria e que o evento é a Imaculada Concepção. Se Maria desfizer a aliança com Deus e deixar de ser virgem, talvez sua punição seja penar no Sheol, o inferno judaico, daí o temor de Maria em face da insistência de J em consumar o casamento

194 No original: And though she was certainly intelligent and imaginative, he was far more broadly educated. In fact, it wouldn't be unkind to say, and he brought himself to confess it in the torment of his most rational moments, that a good many of the most beautiful things he said to her she failed to understand.

195 No original: "the tortures of the underworld".

196 No original: "the woman's very position in the event must give one thoughts upon" 
De qualquer forma, o casamento acontece e $\mathrm{J}$ apenas espera que o tempo reverta a situação e que eles possam viver como um casal normal. A vida de ambos depois das bodas, completamente omitida do relato bíblico, é relatada no conto não em seus aspectos rotineiros, mas em um tom mais psicológico: a felicidade de $\mathrm{J}$ é evidente, iluminam sua vida suas convicções de mundo: "tudo se tornou impressionantemente fácil para ele, os detalhes mais comezinhos da existência lhe davam imenso prazer: uma trilha de formigas, por exemplo, ou a cor de um pedaço de madeira, ou um seixo, as marcas das pegadas dela na areia"197 (JM, p.114). Para completar tal felicidade, somente a consumação do casamento, e J espera pelo momento certo, algumas vezes pacientemente, noutras não. Em seus momentos de desespero, ele pensa estar condenado a passar o resto de sua existência sem jamais tocar o corpo de Maria. Em uma noite em que ele a encontra nua no quarto, tenta, novamente, convencê-la a fazer amor. No entanto, mais uma vez, ela recusa, agora oferecendo um motivo: está grávida, e "sua gravidez era um ato de Deus" (JM, p.117) ${ }^{198}$

Quando o José bíblico ficou ciente da gravidez de Maria, ele pensou em "repudiá-la secretamente" (Mt 1,9). Se José sentiu raiva, tristeza ou desespero, tais sentimentos foram ignorados por Mateus. No Novo Testamento, como no Antigo, sentimentos e pensamentos que não são cruciais para a narrativa são desconsiderados: eles podem ser, como no caso de José, apenas sugeridos e demandam interpretação (Auerbach, 1987 , p. 9). O José bíblico parece reagir da forma esperada pela sociedade de seu tempo - rejeitar a mulher que o traiu — mas a interferência do anjo é um elemento extremamente importante para a mudança de comportamento de José e sua inserção na história de Jesus. José aceita as explicações do anjo e, como um homem que obedece ao Senhor, faz exatamente o que lhe é ordenado: confirma Maria como sua esposa e não a "conhece" até o nascimento de Jesus (Mt 1,20-25).

Na história de Coover, J demonstra o que a Bíblia não conta: como a revelação de Maria afetou os sentimentos de seu marido. O elemento determinante, nesse caso, é a não aparição do anjo para fornecer explicações a J. Coover muda o texto bíblico ao considerar esta passagem sob uma perspectiva humana, e não divina. $\mathrm{O}$ mundo de $\mathrm{J}$, ao contrário do de José, é emoldurado por uma esfera completamente

197 No original: "[e]verything became remarkably easy for him, the dullest detail of existence provided him an immense delight: a parade of ants, for example, or the color of a piece of wood or a pebble, her footprint in the dust."

198 No original: "her pregnancy was an act of God". 
humana, sem qualquer interferência de uma deidade, pelo menos uma interferência da qual ele seja consciente. Em uma determinada noite em que estava caminhando pela praia, J vive um momento de epifania, de transcendência, no qual ele vislumbra um sentido maior para sua vida, além de suas próprias convicções. E, embora ele reconheça a importância do momento, ele o nega em seguida, relegando-o a uma ilusão:

não, não foi maravilhoso, não, seria um absurdo pensar sobre isso desta forma ou sobre qualquer outra beleza natural, mas foi como se pudesse ser maravilhoso, como se em algum lugar residisse uma beleza em potencial, que não existia antes, uma mera fagulha, obviamente, apenas uma ilusão" [...] (JM, p.115). ${ }^{199}$

$\mathrm{Na}$ interpretação de Kennedy, a passagem acima demonstra que J é incapaz de "admitir para a beleza uma existência maior do que o escopo de seu intelecto, mesmo quando isto é evidente em seu coração" (1992, p.43) ${ }^{200} \mathrm{~A}$ única rendição de J em relação aos seus sentimentos e emoções é em seu imenso amor por Maria. É para ela que ele transfere todo o burburinho de emoções que viveu enquanto estava na praia, é através dela que ele reafirma, não uma dimensão religiosa ou divina, mas uma dimensão humana, a única que ele verdadeiramente aceita. Talvez seja esta a razão pela qual os sonhos que ele teve naquela noite — poderia ter sido o anjo? - "infelizmente nunca foram lembrados" (JM, p.115). ${ }^{201}$

$\mathrm{J}$ parece negar qualquer forma de transcendência, qualquer coisa que não possa ser baseada em termos racionais. Seu amor por Maria e seu casamento introduzem uma nova dimensão em sua vida, o que, de alguma forma, abala suas convicções. No entanto, ele tenta, a todo o momento, racionalizar seus sentimentos, embora na maioria das vezes ele se sinta incapaz de fazê-lo. Apesar de seus medos e dúvidas, no entanto, ele decide casar-se com Maria porque "não há alternativa além

199 No original: "It was not, it was not beautiful, no, it would be absurd to think of this or any other natural composite as beautiful, but it was as though it could be beautiful, as though somewhere there resided within the potentiality of beauty, not previously existent, some spark after all, only illusion of course [...]

200 No original: "to admit to the existence of a beauty in existence greater than the scope of his intellect, even when it is made evident to his heart"

201 No original: "unfortunately he could never later recall". 
da morte" (JM, p.112) ${ }^{202}$ e ele prefere enfrentar as conseqüências de suas escolhas.

Coover retrata J, segundo McCaffery, como o precursor paródico do existencialista moderno, "(...) ele se esforça para encontrar sentido e significado nos eventos aparentemente irracionais de sua vida" (1982, p.62-63). ${ }^{203} \mathrm{~J}$ tenta, em um sentido Kierkegaardiano, existir verdadeiramente, ou seja, lutar, esforçar-se, encontrar oposição, vivenciar a paixão (...) tomar decisões, e não ficar ao sabor da maré, (Jones, 1969,. p. 214) ${ }^{204}$. Sua decisão de casar-se com a mulher que ama, suas tentativas de consumar o casamento, sua recusa em permitir que qualquer fator externo decida por ele demonstram que $J$ realmente acredita que é livre e responsável por seu destino, até o momento em que enfrenta a gravidez de Maria. Depois deste evento, sua luta para confrontar as dimensões humana e divina e escolher entre uma delas termina por arrasá-lo.

O José bíblico confia cegamente nas decisões de Deus e condiciona sua existência a elas. As ações de José podem ser interpretadas de acordo com a noção de escolha proposta por Kierkegaard, uma idéia fundamental em sua filosofia. Para Kierkegaard, o que as pessoas fazem de suas vidas não depende da compreensão de sistemas específicos de conceitos, mas, sim, das escolhas que elas fazem. Ele reconhece três diferentes tipos de escolha: a estética, a ética e a religiosa. O estágio estético implica uma maneira de viver na qual o objetivo é lutar contra o sofrimento e principalmente contra o tédio. Para se atingir tal objetivo, a escolha estética é caracterizada por um hedonismo sofisticado e romântico. Na interpretação de Jones (1969, p. 20), na fase estética não importa o tipo de escolha porque não fará nenhuma diferença caso tal escolha venha a ser boa ou má.

Já o estágio ético opõe-se ao estético no sentido de que ele implica uma escolha séria, baseada em regras, deveres e exigências, ou seja, baseada em um código ético. Para Jones, a escolha ética é problemática porque "as pessoas devem decidir como os seus códigos se aplicam às diversas situações concretas em que elas se encontram (1969, p. 220). ${ }^{205}$ Por conseguinte, é importante saber se as pessoas realmente 202 No original: "there was no alternative short of death"

203 No original: "as a slightly parodic forerunner of the modern existential man; (...) he strains to find meaning and significance in the seemingly irrational events of his life" 204 No original: "to struggle, to strain, to encounter opposition, to experience passion (...) to make decisions, not to drift with the tide"

205 No original: "the ethic way is problematic because "men must decide how their codes 
escolheram seu código ou foram inseridas nele pelas circunstâncias. No último caso, o estágio ético atinge uma dimensão contraditória que é suprimida pela passagem do estágio ético para o religioso, a única forma, segundo Kierkegaard, de resolver a contradição. Kierkegaard utiliza como exemplo a história de Abraão: quando Deus pede a ele que sacrifique seu filho Isaac, Abraão precisa enfrentar a transgressão de uma regra universal, o assassinato de seu próprio filho. Como nenhum critério racional pode ajudá-lo, sua única saída é o "salto de fé", pelo qual ele aceita as condições da exigência divina. Ocorre então uma suspensão do estágio ético em favor do religioso (Kierkegaard, 1954, p. 69-72).

O salto de fé caracteriza um comprometimento apaixonado com Deus, porque a afirmação da fé é o oposto do desespero da dúvida (Jones, 1969, p. 223). Para Kierkegaard, (1959, p.354) "[s]omente através de um relacionamento infinito com Deus [podem] as dúvidas serem apascentadas, somente através de um relacionamento infinitamente livre com Deus a ansiedade [pode] ser transformada em alegria". ${ }^{206}$ (1959, p.354). O José bíblico parece aceitar tal noção: depois da visita do anjo, ele parece ter percebido que Deus fez a escolha por ele, portanto, ele está livre da ansiedade e será salvo (Jones, 1969, p. 224). O salto de fé de José o habilita a suportar os deveres exigidos pelas decisões divinas e as apresenta como verdades inquestionáveis.

No conto de Coover, no entanto, $J$ age de forma diferente: ele é incapaz de efetuar um salto de fé porque não acredita que possam escolher por ele. $\mathrm{J}$ até mesmo duvida de Deus: quando Maria fala da gravidez como um ato divino, ele imagina o que "levou Deus a fazer uma coisa tão inútil e, em certo sentido, vulgar" (JM,p. 117). ${ }^{207} \mathrm{O}$ existencialismo de J é mais próximo de Sartre e Nietzsche do que de Kierkegaard. A filosofia existencialista de Nietzsche e Sartre considera, na interpretação de Jones (1969, p.418), a situação do homem em um mundo sem Deus: Nietzsche por anunciar a morte de Deus, e Sartre, por postular que a existência ou inexistência de Deus não faz diferença para a vida das pessoas $(1987$, p.22). Assim que se libertam de "todas as ilusões que toldam a visão da maioria das pessoas sobre si mesmas

apply to the various concrete situations in which they find themselves" 206 No original: "[o]nly by an infinite relationship to God [can] doubt be calmed, only by an infinitely free relationship with God [can] anxiety be transformed into joy".

207 No original: "had brought a God to do such useless and well, yes, in a way, almost vulgar thing." 
e sobre seu mundo (Jones, 1969, p. 418) ${ }^{208}$, elas são capazes de agir, de ser totalmenre rsponsáveis por sua própria existência. $\mathrm{O}$ fato de $\mathrm{J}$ considerar Deus "um deus" demonstra que até aquele momento o anúncio da gravidez de Maria - ele havia concebido a sua vida em mundo sem Deus, pelo menos um Deus no sentido que Maria confere a ele: o Deus que interfere no destino das pessoas. Nas palavras de Thomas Kennedy, não é que J "não acredite em Deus, apenas sua fé em seu próprio intelecto é maior do que sua fé no julgamento de Deus" (1992, p. 43). ${ }^{209}$ "Para J, era inimaginável que Deus pudesse se envolver nos tediosos assuntos pessoais deste ou daquele ser humano, considerando-se a enorme desimportância de um para o outro" (JM, p. 117). ${ }^{210}$ É difícil para J aceitar a explicação de Maria, já que ele é "incapaz de reconciliar tal explicação com uma concepção racional de Deus" (McCaffery, 1982, p. 63). ${ }^{211}$ Quanto mais pensa sobre o assunto, mais confuso J fica. A única saída que ele encontra é incluir o evento no rol dos absurdos inescrutáveis da vida (JM, p. 117), ${ }^{212}$ talvez como uma forma de preservar a própria sanidade. A gravidez de Maria é um fato, e, a não ser que ele a considere que ela lhe foi infiel, ou que seja mentalmente instável a ponto de inventar a história sobre Deus, ele não consegue encontrar qualquer outra explicação racional para o fato. Assim, na tentativa de preservar algum rumo em sua vida, ele escolhe aceitar a explicação fornecida por ela e retorna à sua rotina, que agora inclui, além de seu ofício de carpinteiro, dedicar-se à sua esposa, cujo estado exige cuidados.

Ao contrário de José, o salto de fé de J é por Maria, porque ele a ama, e também por si mesmo. Sua rendição pode ser vista como um ato de sobrevivência, mais do que covardia. A menos que ele faça o que o José bíblico considerou fazer, ou seja, deixar Maria, ele precisa enfrentar um conflito interno: Maria diz a verdade ou não? J prefere ignorar a questão, reconhecendo que ela vai além "de todos os preceitos da ra-

208 No original: "the illusions that cloud most men's visions of themselves and of their world".

209 No original: "does not disbelieve God, but his faith in his own intellect is greater than his faith in the judgment of God".

210 No original: "It was simply unimaginable to $[\mathrm{J}]$ that any God would involve himself in the tedious personal affairs of this or any other human animal, so inutterably [sic] unimportant were they to each other."

211 No original: "because he is unable to reconcile it with any rational conception of God."

212 No original: ."the rest of life's inscrutable absurdities" 
zão" (JM, p. 117) ${ }^{213}$, consciente de que sua escolha pode significar o fim de todas as suas ilusões em relação a Maria e ao casamento de ambos, o que, de fato, acontece. J não admite a interferência de Deus em sua vida, mesmo sofrendo as consequências disso. Na Bíblia, José aceita e acredita que o filho de Maria é especial. A maneira de J considerar Jesus é subversiva em relação à narrativa evangélica porque ele não reconhece em Jesus a figura do Messias, o Salvador, o filho de Deus, enfim, a verdade suprema que os evangelhos empenham em demonstar

O nascimento de Jesus, o grande acontecimento do cristianismo, é recontextualizado no conto. No evangelho de Lucas, Jesus nasceu em Belém porque José e Maria viajaram até a cidade para serem recenseados, de acordo com um decreto das autoridades (Lc 2,1-4). Como não havia lugares disponíveis para hospedagem, tiveram que alojar-se em um estábulo, onde Maria veio a dar à luz. Um anjo avisou os pastores que viviam por perto que Jesus havia nascido e eles se dirigiram a Belém para vê-lo. Lá, encontraram Maria, José e o menino deitado em uma manjedoura (Lc 2,16).

No conto, Coover relata o nascimento de Jesus sob um ponto de vista radicalmente diferente. Pouco é dito sobre a viagem, somente que veio "em má hora" - em se considerando o estágio avançado da gravidez de Maria e as péssimas condições do tempo (JM, p. 17) ${ }^{214}$ Coover omite informações já fornecidas pela narrativa de Lucas. Um aspecto importante enfatizado por Coover em seu relato do nascimento de Jesus é como o evento afeta J: "foi - aquele estranho momento do parto - o momento mais místico de $\mathrm{J}$, seu único e inquestionável vislumbre de toda a existência, ainda assim, um momento ao qual ele mais tarde renunciou, desnecessário dizer, mais tarde compreendido à luz de suas remoídas e torturadas emoções" (JM, p. 118). ${ }^{215}$ Tal momento expõe, de forma definitiva, a condição humana e existencial de J: embora ele sinta que exista algo de especial no nascimento da criança, como no momento de sua primeira epifania à beira da praia, J renega o momento. Em vez de pensar na criança como filho de Deus, como Maria lhe havia dito, para J Jesus representa seus piores sofrimentos, o fim de sua forma estruturada e racional de perceber o mundo. Ao escolher re-

213 No original: "all mandates of his reason."

214 No original: "ill-timed."

215 No original: "[i]t was-that moment of the strange birth-J's most mystic moment, his only indisputable glimpse of the whole existence, yet one which he later renounced, needless to say, later understood in the light of his overwrought and tortured emotions." 
nunciar à esfera divina que se abre para ele pelo nascimento de Jesus, J recusa-se a fazer parte do mito da Imaculada Concepção e, consequentemente, da vida de Jesus e de todo o processo da cristandade.

Sua escolha é marcada pela sua indiferença em relação ao menino e vice-versa. Após tentar, sem sucesso, estabelecer uma relação afetiva com a criança, $J$ "preferiu não ser mais incomodado por qualquer outra forma de existência" (JM, p. 118). ${ }^{216}$ Sua vida torna-se praticamente sem sentido, o único acontecimento digno de nota é a consumação do casamento, ocorrida alguns meses depois do nascimento do menino. E mesmo esse evento ocorre em um contexto tão diferente do imaginado por $\mathrm{J}$ que ele até mesmo duvida que o fato tenha acontecido. $\mathrm{O}$ casamento termina com a morte de $\mathrm{J}$, anos depois. Ironicamente, J e Maria seguem o princípio cristão de que o casamento só termina com a morte de um dos cônjuges (Rom. 7:2). J, já senil, morre em uma taverna, num ataque de tosse provocado pela tuberculose, com o rosto mergulhado em uma taça de vinho tinto (JM, p.119). J nega o mito cristão, no entanto, morre "inundado pelo sangue simbólico do filho mítico" (Cope, 1986, p. 24). ${ }^{217}$ A cena ecoa ironicamente a Eucaristia, na qual o sangue de Jesus redime os pecados da humanidade. Pouco antes de morrer, $\mathrm{J}$ percebe que "sua vida, afinal, não foi mais nem menos do que ele esperava (...), apesar de tudo, nada havia de trágico nela, nada para se ruminar, ao contrário" (JM, p. 119) ${ }^{218}$ A conclusão de J parece derivar principalmente de seu desconhecimento e da negação de seu papel na vida de Maria e do menino. Por recusar-se a fazer parte da história deles, ele permanece um homem comum, e assim termina seus dias. Ao contrário do José bíblico, J jamais se tornaria um santo.

Coover enfatiza em J's marriage que a interferência de Deus pode não ser sempre a coisa mais certa a se fazer. J leva uma existência infeliz porque Deus se intepõe entre ele e a mulher que ama, ainda que $\mathrm{J}$ rejeite tal noção e lute desesperadamente para fazer suas escolhas. Jesus, cuja mensagem foi a de que devemos perdoar nossos inimigos e amar uns aos outros porque somos todos filhos de Deus, não é capaz de mostrar essa verdade para $J$. A vida de $J$ segue na contramão das personagens bíblicas, porque, ao contrário delas, ele duvida de, e, é até mesmo indiferente, a Deus. J permanece no plano do humano, ele

216 No original: "J grew to prefer not being bothered by any other form of existence."

217 No original: "awash with the symbolic blood of the mythic child."

218 No original: "that [his] life turned out to be nothing more or less than he had expected after all, (...) in spite of everything, there was nothing tragic about it, no, nothing there to get wrought up about, on the contrary." 
não almeja nenhum tipo de transcendência a uma dimensão divina. Além disso, ele nega qualquer intervenção que possa mudar o curso de sua vida que não seja feita por ele mesmo. J é incapaz de apreender a dimensão em que Maria se encontra: sua enigmática e silenciosa caracterização parece enfatizar este aspecto. Ela é intelectual e socialmente inferior a J, mas é a escolhida para partilhar do convívio divino, onde seu papel é central. Neste contexto, a suposta superioridade de J soa irônica, porque ela em nada o ajuda a lidar com Maria e resolver os conflitos entre eles.

Marcos e Lucas enfatizam a importância do sagrado na vida de José - ser o pai terreno de Jesus, receber a visita de anjos, que intermedeiam a relação entre ele e Deus. O narrador de J's marriage aponta para a subversão de tais sentidos através do cancelamento da esfera sagrada e da introdução de elementos puramente humanos que não são considerados na narrativa bíblica: a ênfase na vida sexual de Maria e José, a descrição da consumação do casamento, a indiferença de $\mathbf{J}$ em relação a Jesus. Tais elementos operam como um fundamento pelo qual os leitores interpretam $\mathrm{J}$ como um homem que lutou para direcionar sua vida em um mundo inteiramente humano, mas que falhou por causa da intervenção de Deus. Incapaz de adaptar-se a uma dimensão sagrada, a partir do momento em que J é confrontado com a misteriosa gravidez de Maria passa a viver uma existência infeliz e sua morte é melancólica. Há um questionamento acerca das ações divinas e suas consequências na vida dos homens. A partir das lacunas dos evangelhos, Coover empenhou-se em mostrar que $\mathrm{J}$ viveu e entendeu sua vida como um ser humano e que, fora desse contexto, ele foi incapaz (diferentemente do José bíblico) de construir um sentido para ela. 


\section{Referências}

ANDERSEN, Richard. Robert Coover. Boston: GK Hall, 1981.

AUERBACH, Erich. Mimesis. Perspectiva, 1987. (Coleção Estudos, v. 2).

BÍBLIA SAGRADA. Tradução Ecumênica. São Paulo: Loyola, 1994.

BRADBURY, M., RULAND, R. From puritanism to postmodernism. New York: Penguin, 1992.

COOVER, Robert. Pricksongs \& descants. New York: New American Library, 1970.

COPE, Jackson I. Robert Coover's fiction. Baltimore: Johns Hopkins University Press, 1986.

JONES, W. T. A history of western philosophy. 2. ed. New York: Harcourt, Brace \& World, 1969. 5v. V. 4: Kant to Wittgenstein and Sartre.

KENNEDY, Thomas E. Robert Coover: a study of the short fiction. New York: Twayne, 1992.

KIERKEGAARD, Søren A. Fear and trembling. Translated by W. Lowrie. New York: Doubleday, 1954.

—. Either/or. Translated by W. Lowrie. New York: Doubleday, 1959. Vol. II.

LEE, L. L. Robert Coover's Moral Vision: Pricksongs and descants. Studies in Short Fiction, Newberry, SC, v. 23, n. 1, p. 63-69, 1986.

MCCAFFERY, Larry. The metafictional muse: the works of Robert Coover, Donald Barthelme, and William Gass. Pittsburgh: University of Pittsburgh Press, 1982.

WILKIE, Brian; HURT, James. Literature of the western world. New York: Macmillan, c1992. 2 v. V. 2: Moderns and Contemporaries. 